\title{
Proceedings of the Third Meeting of the EURO Working Group on Operational Research (OR) in Agriculture and Forest Management (EWG-ORAFM)
}

\author{
EDITED BY \\ L. M. PLÀ* AND D. L. SANDARS \\ ${ }^{1}$ Department of Mathematics, University of Lleida, 73 Jaume II, 25001 Lleida, Spain \\ ${ }^{2}$ Natural Resources Management Centre, Cranfield University, Cranfield, Bedfordshire MK43 OAL, UK
}

(First published online 12 May 2008)

The working group, which is concerned with operational research methods and applications to agricultural science in its broad meaning (i.e. including Forest Management and Fisheries), was formed in 2003 within the European Association of Operational Research Societies (EURO). The first meeting of the group was held at the former Silsoe Research Institute in 2004. The group intends to have regular meetings in Europe at approximately yearly intervals, usually within the EURO Conferences. However, the next meeting will be held in 2008 within the British Operational Research Society's OR50 Conference in York, followed by the EURO XXIII Conference in Bonn in 2009 and the EURO XXIV Conference in Lisbon in 2010. The third meeting of the working group, chaired by Dr L. M. Plà of the University of Lleida, with the assistance of D. L. Sandars of Cranfield University and organized as a stream within the XXII EURO Conference, was held at the University of Economics in Prague from 8 to 11 July 2007 where the following papers were read in a set of 10 sessions.

* To whom all correspondence should be addressed. Email: lmpla@matematica.udl.cat 


\section{ABSTRACTS OF COMMUNICATIONS}

\section{Behavioural observations on preference enquiry. T. HUJALA ${ }^{1}$, T. KAINULAINEN ${ }^{2}$ AND P. LESKINEN ${ }^{2} .{ }^{1}$ Department of Forest Resource Management, PO Box 27, University of Helsinki, Finland, ${ }^{2}$ Finnish Forest Research Institute, Metla, PO Box 68, Joensuu, Finland}

Reliable preference elicitation is a prerequisite for socially sustainable application of multi-objective decision-analysis techniques. Previous research (e.g. Belton 1986; Pöyhönen et al. 2001; Hujala \& Leskinen 2006) has shown that cognitive biases may cause conflicting results to emerge when framing the preference enquiry in alternative ways.

In an experiment with 30 individual forest owners, Hujala \& Leskinen (2006) applied different measurement scales in direct rating of preferences. The elicited ratio scale weights were transformed into interval scale and plotted with the original interval scale values. There appeared a significant pattern where ratio scale brought along bigger differences between the goal importances in the high-end than did the interval scale and vice versa (see similar results in Belton (1986)).

To test and refine these findings, the present authors incorporated pairwise comparisons into the preference enquiry. Experimenting with a job selection problem involving 45 forestry students resulted in a substantially milder pattern in the preference mismatch than was observed by Belton (1986) and Hujala \& Leskinen (2006). Nevertheless, it was discovered that changing the reference point impacts the outcome of the analysis.

Potential reasons behind the observed cognitive biases are the anchoring (Buchanan \& Corner 1997) and unadjustment phenomena (Pöyhönen et al. 2001). It is thus recommended to think through carefully both the graphics and the verbal statements around each preference enquiry. Simple transforming of preferences to different measurement scales may result in unintended obscurities. However, one additional viewpoint is that through combining two different weighting methods, one could obtain a reasonable estimate for the measure of preferential uncertainty by assessing the differences between the methods. This may serve as an alternative uncertainty analysis procedure in addition to using pairwise comparison techniques and related statistical models (e.g. Alho et al. 2001).

Keywords: Multi-Objective Decision Making, Forestry Management
Alho, J. M., Kolehmainen, O. \& Leskinen, P. (2001). Regression methods for pairwise comparisons data. In The Analytic Hierarchy Process in Natural Resource and Environmental Decision Making (Eds D. L. Schmoldt, J. Kangas, G. A. Mendoza \& M. Pesonen), pp. 235-252. Dordrecht, The Netherlands: Kluwer Academic Publishers.

Belton, V. (1986). A comparison of the analytic hierarchy process and a simple multi-attribute value function. European Journal of Operational Research 26, 7-21.

Buchanan, J.T. \& Corner, J. L. (1997). The effects of anchoring in interactive MCDM solution methods. Computers \& Operations Research 24, 907-918.

Hujala, T. \& Leskinen, P. (2006). Preferences in interval and ratio scales - An experiment with non-industrial private forest owners. In Proceedings of the Second Meeting of the EURO Working Group on Operational Research $(O R)$ in Agriculture and Forest Management (Ed. L. M. Plà). Journal of Agricultural Science, Cambridge 144, 467-472.

Pöyhönen, M., VRoliJk, H. \& HämäLÄInen, R. P. (2001). Behavioral and procedural consequences of structural variation in value trees. European Journal of Operational Research 134, 216-227.

Timber harvest scheduling in Cuba using a multicriteria approach. R. CABALLERO ${ }^{1}$, T. GOMEZ ${ }^{1}$, M. HERNÁNDEZ ${ }^{1}$, A. LEÓN ${ }^{2}$ AND J. MOLINA ${ }^{1}$. ${ }^{1}$ University of Málaga, Avenida Cervantes $n^{\circ} 2$, 29071 Málaga, Spain, ${ }^{2}$ University of Pinar del Río, Pinar del Río, Cuba

A Multi-Objective Programming model is proposed to solve a timber harvest scheduling problem in Cuba. The formulation of a timber harvest plan involves important economic and sustainability criteria, amongst others. In addition, spatial considerations are also studied and included in the model through the use of integer variables and adjacency sets, so that units in the same adjacent set cannot be clear cut simultaneously. This kind of constraint will allow preservation of many important environmental aspects such as beauty of the landscape or biodiversity, and will also result in reducing soil erosion (Weintraub \& Murray 2006).

It would be preferable to manage different units in the forest for a given time horizon, so that the following five requirements of the decision maker are met:

(i) The annual harvested volumes should be the same.

(ii) Avoidance of clear cutting at early stand ages. 
(iii) Clear cutting of areas older than the maximum rotation duration.

(iv) The Net Present Value (NPV) must be higher than a certain threshold return.

(v) The area covered by each age class should be roughly the same by the end of the planning horizon.

These requirements do not mean optimization of any measure, but rather achievement of certain targets for certain aspects related to sustainable management of a forest. This is the main reason for using a Goal Programming approach, as these types of preferences can be perfectly specified in this kind of model (Gómez et al. 2006). The model also includes some constraints regarding the adjacency relations and lower bounds on the clear cut area and the NPV on each time period. As a result, a complex non-linear, mixed-integer, Multi-Objective Programming problem is established that cannot be solved with an exact solver, requiring the design and implementation of a multi-objective metaheuristic for its resolution.

It was applied to the case of a real forest in Pinar del Río, Cuba. This forest is managed by the Empresa Forestal Integral 'Macurije' and contains exclusively Pinus Caribea L., obtaining interesting and useful results regarding the optimal use of a forest in these several aspects studied.

Then, a Multi-Objective model for timber harvest scheduling was developed, taking into account not only economical aspects, but also sustainability of the forest managed. A multi-objective metaheuristic capable of solving such a complex problem efficiently was also designed and implemented.

Keywords: Forestry Management, Programming, Multi-Objective, Sustainable Development

Gómez, T., Hernández, M., León, M. A. \& Caballero, R. (2006). A forest planning problem solved via a linear fractional goal programming model. Forest Ecology and Management 227, 79-88.

Weintraub, A. \& Murray, A. T. (2006). Review of combinatorial problems induced by spatial forest harvesting planning. Discrete Applied Mathematics 154, $867-879$

Biodiversity and agricultural production planning by Linear Programming. D. L. SANDARS AND E. AUDSLEY. Natural Resources Management Centre, Cranfield University, Cranfield, Bedfordshire MK43 OAL, UK

Policy makers are concerned that contemporary arable farming practices lead to an unacceptable decline in biodiversity, such as farm-land birds.

Model-based, farm-level policy impact analysis is well established using Linear Programming (LP) approaches, for example, Audsley (1981). Environmental pollution, such as the emission of nitrates into water or of greenhouse gases into the atmosphere have been included as multiple objectives to be limited or traded-off against profit (Annetts \& Audsley 2002). These modelling approaches are being developed to include the weeds among crops and stubbles as well as non-crop-land features such as hedges, ditches, woods, and ponds, because these features and their management have an important role as food sources and breeding habitats for birdlife.

At an aggregate level, the optimization of long-term profitability has modelled the response of farmers to changes and choices. This optimization function is being developed to include important non-profit objectives that have a role in the prediction of a rational farmer's response to biodiversity policy. For example, although encouraging greater weed numbers may offend some farmers' views of efficient farming, others may be prepared to forgo profit for less-tangible benefits.

Results show that the cost of providing habitat varies strongly with soil and rainfall and that a policy needs to be designed carefully to create more habitats efficiently.

Important open questions remain. Can the high utility of LP be preserved while recognizing that there is a non-linear relationship between the length of field boundaries, the area of fields and the subsequent performance of field machinery? Can the salient non-profit objectives be identified, quantified and modelled in the LP? Can the preferences of a sub-set of farmers for today's policy choices be used to predict the behavioural response of the wider population of farmers for future, as yet unspecified choices?

This work is currently funded by the Rural Economy and Land Use programme (RELU) of the UK Research Councils.

Keywords: OR in Agriculture, Programming, Multi-Objective, Sustainable Development

Annetts, J.E. \& Audsley, E. (2002). Multiple-objective linear programming for environmental farm planning. Journal of the Operational Research Society 53, 933-943.

AudsLey, E. (1981). An arable farm model to evaluate the commercial viability of new machines or techniques. Journal of Agricultural Engineering Research 26, 135-149.

Prevention or control? An exploration of the tradeoffs between pre- and post-event actions for the management of avian influenza. N. LONGWORTH ${ }^{1}$, R. A. JONGENEEL ${ }^{2}$, H. W. SAATKAMP ${ }^{1}$ AND R. B. M. HUIRNE ${ }^{1}$. ${ }^{1}$ Business Economics Group, ${ }^{2}$ Agricultural Economics and Rural Policy Group, Department of Social Sciences, Wageningen University and Research Centre, 6701KN Wageningen, The Netherlands 
Outbreaks of epizootic animal diseases occur frequently in the European Union. Such outbreaks can have a large impact on producers, the agricultural sector and society as a whole. Avian influenza (AI) has the added complication that human transmission is possible, resulting in illness and sometimes death. The last decade has seen a surprising increase in outbreaks of AI throughout the world.

Three sets of actions (choice variables) can be used to manage the risk of $\mathrm{AI}$ : prevention, monitoring (both pre-event actions), and control (post-event action). Decision makers will need to allocate resources between these three sets of actions to minimize the impacts of AI outbreaks.

The objective of the current research is to develop an economic framework appropriate for exploring the issue of resource allocation for the management of AI at the country level. Some optimal balance must exist between pre-event and post-event actions; this balance will differ between countries and in different situations.

Within the developed framework, the decision problem is to choose the levels of prevention, monitoring and control which maximize the expected annual social welfare across two states of nature: outbreak and no-outbreak. The model consists of relationships between the three choice variables, epidemiological variables, human health variables and economic impacts on producers, consumers and government expenditure.

The framework is illustrated with a case study for the Netherlands, calibrated to a hypothetical base situation of moderate levels of prevention, monitoring and control using positive mathematical programming. Where information was available, plausible functional forms were chosen representing the Dutch situation. First model results clearly demonstrate the complexity of the decision problem; each action has very different marginal costs and benefits which fall on different stakeholders in society and which are dependent on the level of each action. Major uncertainties exist regarding the appropriate functional forms for the epidemiological and human health variables.

The developed framework proved useful to clarify and explore a complex decision problem and can be used to explore the consequences of different management strategies for AI.

Keywords: Disaster and Crisis Management, Economic Modelling, OR in Agriculture

\footnotetext{
Dynamic adjustment and optimizing behaviour of agricultural sector in foot-and-mouth disease outbreak in Finland. J. K. NIEMI AND H. LEHTONEN. MTT Agrifood Research Finland, Economic Research, Luutnantintie 13, FI-00410 Helsinki, Finland
}

Foot-and-mouth disease (FMD) is one of the most important infectious animal diseases in the world. FMD virus can infect pigs, cattle, goats and sheep. Export interferences are among the most important economic consequences of FMD.

Given scenarios on the scale of FMD outbreaks in Finland, our goal is to postulate a model which addresses these two questions:

(i) To which extent does the disease outbreak affect the quantity of livestock production and financial losses of farmers, the processing industry and government?

(ii) Would it be profitable to mitigate the spread of the disease with emergency vaccination?

The model consists of a demand model and a supply model, which jointly simulate livestock markets on a monthly basis. The demand model is a set of demand equations. They stratify (derived) demand for dairy products, beef and pig meat into domestic demand for each Finnish product, demand for nonFinnish product imported and demand for products exported. Exports are separated to EU and non-EU destinations.

The supply is modelled by solving supply decisions with a structural-form dynamic programming model (cf. Niemi et al. 2006). The model takes into account profit-maximizing behaviour and the dynamics of production through insemination decisions. Supply of meat and raw milk is very inelastic in the short run, whereas in the long run farmers can adjust animal stock and productivity. Dairy processing, subject to the balance of milk fat and skimmed milk in dairy products, can be adjusted.

There are distinct sector models for competitive pricing behaviour and monopoly behaviour motivated by highly concentrated processing industry in Finland.

The Bellman equation was solved by backward induction, which ensures the necessary and sufficient conditions for optimality. Emergency vaccination is analysed with real options, which is consistent with dynamic programming.

The first results suggest that economic losses due to FMD, driven by reductions in exports and domestic prices, are not easily mitigated through supply optimization, even in the case of domestic monopoly, because domestic supply and demand are relatively inelastic.

Keywords: Optimization, Dynamic Programming, Simulation, Foot and Mouth Disease, Exports, Vaccination Decisions, Real Options

Niemi, J. K., Lehtonen, H. \& Pietola, K. (2006). Effects of an animal disease shock on meat markets and producer income. Acta Agriculturae Scandinavica, Section C-Food Economics 3, 138-150. 
Identification of financially compromised areas in the agrarian sector. C. R. GARCIA-ALONSO AND L. M. PEREZ-NARANJO. Management Department, ETEA Business Administration Faculty, University of Córdoba, Escritor Castilla Aguayo $n^{\circ} 4$, 14004, Córdoba, Spain

The spatial analysis of both autocorrelation (Moran's I, Geary's C and Getis and Ord's Gd(I) and Gd(II)) (Anselin 1995) and Bayesian (Besag et al. 1991) Conditional Auto-Regressive model scores obtained from a financial analysis is a useful tool to locate financially compromised areas in the agrarian sector (Pérez-Naranjo \& García-Alonso 2005). These areas identify the places where specific strategic groups of farms (productive strategies where the value-added rate of a crop type is dominant) might not be able to maintain their structure because of not being profitable enough (financial risk: probability of having a total net margin less than zero). Maps obtained by Kernel estimation using autocorrelation and Bayesian scores evaluating the financial risk show different, sometimes conflicting, spatial projections difficult to interpret. Potential hot-spots (darker zones) have different shapes and, due to the geographical proximity of the neighbourhoodsmunicipalities, Kernel estimation can misclassify some municipalities.

A Multi-Objective Evolutionary Algorithm (MOEA) has been developed and tested (Zitzler 1999) in order to deal with different spatial projections to obtain a unique classification for financially compromised areas. This MOEA takes into consideration as objectives the autocorrelation and Bayesian means as well as their corresponding standard deviations. The geographical distance between municipality capitals was also included as an objective to be minimized.

Once a seed, initial solution set, is generated, MOEA processes better and better municipality groups until a set number of generations is reached or a convergence criterion (statistical error) is satisfied. Only feasible and non-dominated solutions are considered for each generation. A simple tournament has been developed to select solutions considering three different fitness functions: weighted objectives, ranking and weighted ranking. Crossover can be simple or double and, finally, mutation can be random or distance-based (the element selected to be mutated is that which shows the maximum distance from the rest in the group). Feasible and non-dominated solutions from every run are saved in a solution pool.

On analysing the financial risk of a horticultural farm sample (345 farms), results showed the existence of several financially compromised areas in Andalusia (hot-spots). The probability that each municipality has to belong to a specific hot-spot has been evaluated, represented on a map and compared to Kernel projections.
Keywords: Multi-Objective Evolutionary Algorithm, Spatial Analysis, Financial Sustainability

Anselin, L. (1995). Local indicators of spatial association: LISA. Geographical Analysis 27, 93-115.

Besag, J., York, J. \& Mollié, A. B. (1991). Bayesian image restoration with two applications in spatial statistics. Annals of the Institute of Statistical Mathematics $\mathbf{4 3}$, $1-59$.

Perez-naranjo, L. M. \& Garcia-alonso, C. R. (2005). La distribución espacial de la renta en las explotaciones hortícolas andaluzas. Cuadernos Geográficos 37, 41-58.

ZITZler, E. (1999). Evolutionary algorithms for multiobjective optimization: methods and applications. $\mathrm{PhD}$ thesis, Swiss Federal Institute of Technology, Zurich.

Real options and crisis events: the control of footand-mouth disease epidemics. L. $\mathrm{GE}^{1}$, O. GUTIÉRREZ ${ }^{2}$, M. MOURITS ${ }^{1}$ AND R. HUIRNE ${ }^{1} .{ }^{1}$ Business Economics Group, Wageningen University, Hollandseweg 1, 6706KN, Wageningen, The Netherlands, ${ }^{2}$ Department of Business Economics, Universitat Autònoma de Barcelona, Edifici B-Campus de Bellaterra, 08193 Cerdanyola del Vallès, Barcelona, Spain

Crisis events with potentially disastrous consequences are often characterized by an unknown 'turning moment' after which the crisis is under control. This feature has implications for rational choice of timing for crisis intervention measures.

The current paper analyses such an issue in the control of foot-and-mouth disease (FMD) epidemics. Due to its potentially disastrous damage to the national economy, FMD is one of the most feared highly contagious animal diseases, especially for export countries (Mahul \& Gohin 1999). In the Netherlands, the control of FMD epidemics is an important element in national crisis management.

To provide a rational basis for decision making, it is important to clearly define the consequences of an FMD crisis. Based on McInerney et al. (1992), the total expected economic loss of an epidemic is decomposed into three parts:

(i) The expected loss in terms of production value.

(ii) The expected expenditure of control actions.

(iii) The expected costs in the worse-case scenario.

The evolution of an FMD epidemic is modelled as a process with an unknown-date event (turning moment), following closely the approach described in Gutiérrez \& Ruiz-Aliseda (2006). It is assumed that before this turning moment, the epidemic grows exponentially and afterwards the epidemic also decays exponentially, with both growth and decay rates estimated from epidemiological models. The decision problem is to choose an optimal time, $t$, in order to minimize the economic loss at a national level. 
With epidemiological modelling, the density function of the turning moment, $\tau, f($.), can be estimated. As illustrated in the paper, depending on the form of the density function, $f($.), this can lead to closed-form solution or the optimal timing, $t^{*}$, has to be solved numerically. A numerical example is built to demonstrate the possible outcomes of the model, which is based on the Dutch situation and simulated FMD outbreaks.

It is concluded that in managing a crisis event like FMD epidemics in the Netherlands, attention should not only be paid to the speed of interventions but also to their timing, which could avoid unnecessary control costs in some situations.

The current research is part of the project 'Discovering Real Options in the Control of Footand-mouth Disease' funded by the Netherlands Organization for Scientific Research (NWO).

Keywords: Disaster and Crisis Management, Decision Analysis, Risk Analysis and Management

Gutierrez, O. \& Ruiz-Aliseda, F. (2003). Real Options with Unknown-date Events. Discussion Paper No. 1378. Chicago, USA: Northwestern University, Centre for Mathematical Studies in Economics and Management Science.

Mahul, O. \& Gohin, A. (1999). Irreversible decision making in contagious animal disease control under uncertainty: an illustration using FMD in Brittany. European Review of Agricultural Economics 26, 39-58.

Mcinerney, J.P., Howe, K.S. \& Schepers, J. A. (1992). A framework for the economic analysis of disease in farm livestock. Preventive Veterinary Medicine 13, 137154.

\section{Optimizing the aggregate production planning in a sugarcane milling company. R. PAIVA AND R. MORABITO. Department of Production En- gineering, Federal University of São Carlos, CP 676, 13565-905 São Carlos, São Paulo, Brazil}

The current paper presents an optimization approach for the aggregate production planning of a Brazilian sugar and alcohol milling company. The approach involves the evaluation of different technical and economical parameters, which are used in a mixed integer linear programming model that represents the sugar, alcohol and molasses production system, including decisions on the quantity of sugarcane crushed, selection of industrial processes and inventory of final products. Computational results using actual data and the CPLEX software are reported.

Keywords: Industrial Optimization, OR in Agriculture, Programming, Integer
Economical impact of sugar and bioethanol production from sugarcane by a Computable General Equilibrium Model for Colombia. L. C. MANRIQUE RUIZ, E. G. FRANCO AND G. GONZÁLEZ. Facultad de Ingeniería, Centro de Investigación en Tecnologias Avanzadas de Decisión, Universidad de la Sabana, 05791 Bogotá, Chía, Colombia

The Colombian sugar companies need to produce ethanol from sugarcane without having a significant impact on sugar production. However, the impact is already notable, since the cost of sugar and food has already risen in Colombia due to production of ethanol (Klotz 2006). This problem can be analysed using the Theory of General Equilibrium which helps to identify the prices and quantities of equilibrium in different markets. This abstract presents a Computable General Equilibrium Model (CGE) for sugar and bioethanol production from sugar cane in Colombia.

A Social Accounting Matrix (SAM) was used to develop the model. The objective was to investigate the response to sugar production policy changes, while maintaining all other economic sectors constant, by asking, 'what happens if ... ?'(Ceteris paribus).

To build SAM the following information was collated:

- National accounts data from the Columbian National Department of Statistics (DANE),

- Colombian sugar sector data from the Columbian Association of Sugar Cane Growers (ASOCAÑA),

- Ethanol demand and production data from different sources,

- Data on household accounts, and

- Other data from other economic institutions.

These datasets were used to identify, for each economical sector, the set of input-output accounts, which together cover the entire national economy as a combined set of input-output accounts (Cicowiez 2004). The sectorial input-output accounts and their corresponding interactions form SAM. SAM was statistically calibrated before scenarios were solved using the optimization software GAMS-CPLEX (http://www.gams.com), with the objective of maximizing earnings. The solutions identify the quantitative economic impacts of a strategic change in sugar production policies and/or the economic relationships between sectors (Hosoe 2004).

The main conclusion from this study is that SAM of 2004 helped in identifying that the price of ethanol has a big impact affecting sugar prices, capital investment and wages. One of the most affected sectors was the service sector.

Keywords: Social Accounting Matrix, Computable General Equilibrium, Sugar, Ethanol 
Cicowiez, M. \& Di gresia, L. (2004). Equilibrio General Computado: Descripción de la Metodología. Trabajo Docente 7.: Universidad Nacional de la Plata, La Plata, Argentina.

Hosoe, N. (2004). Computable General Equilibrium Modelling with GAMS. National Graduate Institute for Policy Studies, Tokyo, Japan.

Klotz, B. (2006). Integración de las ciencias caso énfasis bioprocesos, diversificación del sector azucarero en Colombia. Universidad de la Sabana, Chía, Colombia.

\section{Operational Research in agriculture: the use of as- signment model. M. S. SAUIAN. Faculty of IT and Quantitative Sciences, Universiti Teknologi MARA 40450 Shah Alam, Malaysia}

Operational Research (OR) has been applied in multifarious fields of research and business endeavours. It includes optimization in business and industry, manufacturing, economics, engineering, transportation, distribution, strategic planning and even in the domain of the sciences.

In Malaysia, the application of OR is more dominant in the use of optimization in fertilizer usage, cross-breeding, crop yield, farm planning as well as in livestock distribution (Samik \& Chwee 1999). However, with the government focussing on enhancing the agricultural sector, more usage in this sector is envisaged (The Economic Planning Unit 2006).

The agricultural sector is not neglected in the Malaysian development agenda, because it accounted for 0.131 of the overall workforce in 2006 (Department of Statistics, Malaysia 2007). The oil palm plantation has become the largest sector in terms of area after it surpassed the rubber plantation sector in 1997. In 2006, the total area planted with oil palm reached $4165215 \mathrm{~h}$ (Malaysian Palm Oil Board 2006).

Koperasi Johor Plantation (KJP) is one of the state agencies which embarked on the plantation of oil palm. It is a small-sized plantation which has a total area of 1100 acres $(450 \mathrm{~h})$. Traditionally, it uses the unsystematic way of plucking fruits by just assigning two supervisors to oversee the 30 or so workers harvesting the fruits. However, in early 2006 the manager tried to deploy the workers in a more efficient and better way. By working with the present authors, a more systematic approach has been introduced.

First, the competence or the harvesting skill level of each of the workers was determined. The workers were divided into 11 groups and KJP was divided into 11 zones. Each group constituted of three workers of almost the same level of competence. Using the assignment model, workers were assigned according to groups and zones of operations in plucking the oil palm fruits. The exercise was also performed by applying within-group assignment.
The results indicated that the group assignment increased the daily yield contribution by $6.41 \%$ as compared to a situation of no assignment. In addition to that, the assignment encouraged team-work among the workers. However, by using the within-group assignment it increased only by $2 \cdot 44 \%$ as compared to a no-assignment scenario. Thus, the results of the exercise had a benevolent impact as it benefited both the workers as well as the organization.

\section{Keywords: OR in Agriculture}

Samik, M. N. \& Chwee, C.P. (1999). Operations research application in agriculture. Annual Review of Operations Research and Management Science, Malaysia 2, 13-18.

Department Of Statistics Malaysia. (2007). Malaysian Economics in Brief, March 2007. Department of Statistics Malaysia, Putrajaya, Malaysia.

The Economic Planning Unit. (2006). Ninth Malaysian Plan 2006-2010. The Economic Planning Unit, Prime Minister's Department, Putrajaya, Malaysia

Malaysian Palm Oil Board. (2006). Review of the Malaysian Palm Oil Industry, Malaysian Palm Oil Board, Selangor, Malaysia.

Application of decision theory methods for a Community of Madrid soil classification case. J. ANTON, J. GRAU, A. TARQUIS, A. SAA AND E. SÁNCHEZ. Escuela Technica Superior de Ingenieros y Agronomos, Universidad Politechnica de Madrid, Av. Complutense s/n, 28040 Madrid, Spain

To evaluate soil quality from soil data profiles, for agricultural production, forestry and environmental purposes, the authors started with 122 i-soils from a Survey of the Lands of Community of Madrid (CM) (Gallardo et al. 2005) using the Riquier et al. (1970) system, intended for land use planning decisions.

A multi-attribute additive value function was adopted, giving a $(0,1)$ Quality Index, QI:

$q_{i}=\sum_{j=\mathbf{1}}^{n^{\prime}} w_{j} f_{j}\left(x_{i j}\right) \equiv \sum_{j=\mathbf{1}}^{n^{\prime}} w_{j} y_{i j}$

The $13 j$-attributes were selected from the CM study in order to be able to qualify the different scenarios and also be as independent as possible. They were: annual rain, vegetative period, USLE-C (tolerable soil losses), slope, actual erosion, drainage, permeability, stoniness, sealing and crusting risk, $\mathrm{pH}$, calcium carbonate and cation exchange capacity (CEC).

For (1) the data $x_{i j}$, the result of measures or categories were converted in $(0,1)$ 'more is better' Attribute Quality Indexes (AQI) $y_{i j}=f_{j}\left(x_{i j}\right)$, becoming even negative to penalize some scenarios, through elicited Attribute Value Functions (AVF: $f_{j}$ ).

The QI case study results agreed with the worst attribute Index Class SQ (I-VIII) obtained in CM Survey. They pointed out the complementary 
applicability of the proposed QI method that shows how well variables affect quality, separating the worst classes VI-VIII.

In the search of other criteria aggregation models (Zopounidis \& Doumpos 2004), the authors suggest a QI-SQ-combined Quality Index (CQI) $c q_{i}$, starting from $q_{i}$ in (1) and lowering it towards $k$-classes IQS values $i q s(k)=0 \cdot 1(10-k)$ :

$c q_{i}=\inf _{k=1, \ldots, 8}\left\{q_{i} \alpha_{k i}+i q s(k)\left(1-\alpha_{k i}\right)\right\}$

The 'fuzzy sets' weights $\alpha_{k i} \in(0,1)$ are the products,

$\alpha_{k i}=\prod_{j}\left\{\left(1-\delta_{i k j}\right) /\left(1-q_{i}\right)\right\}$

of the $j \in(1,13)$ factors for which $\delta_{i k i}>q_{i}$, and the $\delta_{i k i}$ are defined as going from 0 to 1 with $y_{i j}=f_{j}\left(x_{i j}\right)$, when $x_{i j}$ goes from a starting CQS-threshold $U_{k j}$ to a worse absolute $V_{k j}$ one, taking the higher $\delta_{i k j}$ in both senses for attributes like $\mathrm{pH}$. The threshold $U_{k j}$ and $V_{k j}$ will have to be elicited using Soil Science Experience.

Keywords: Quality of Soils, Additive Valuation, Criteria Aggregation, Value Function

Gallardo, J., SaA, A., Hontoria, C. \& Almorox, J. (2005). Mapa Agrológico: Capacidad Agrológica de las tierras de la Comunidad de Madrid. Madrid, Spain: Direccion General de Urbanismo y Planificación Regional, Communidad de Madrid.

Riquier, J., Bramao, D. L. \& Cornet, J. P. (1970). A New System of Soil Appraisal in Terms of Actual and Potential Productivity. Rome, Italy: Food and Agriculture Organization, Soil Resources, Development and Conservation Service, Land and Water Development Division.

Zopounidis, C. \& Doumpos, M. (2004). Multicriteria decision aid in classification problems. Newsletter of the EURO Working Group on Multiple Criteria Decision Aiding 3, 1-3.

Precision technologies in pig fattening-how much do they pay? J. K. NIEMI ${ }^{1}$, K. PIETOLA ${ }^{1}$ AND M.-L. SEVÒN-AIMONEN ${ }^{2} .{ }^{1} M T T$ Agrifood Research Finland, Economic Research, Luutnantintie 13, FI-00410 Helsinki, Finland, ${ }^{2}$ MTT Agrifood Research Finland, Biotechnology and Food Research, FI-31600 Jokioinen, Finland

Purchases of feed and piglets constitute almost $0 \cdot 9$ of the variable costs of pig fattening in Finland. Moreover, the timing of slaughter, jointly with feeding and genotype, affects the pig's carcass qualityadjusted value. Pigs are typically fed with 1-3 different feed mixtures during fattening. The pig's potential use of energy and protein in feeds change as it grows. Genetic variation causes this potential to differ between pigs. Thus, it is valuable to have information on how feeding regime and slaughter timing affect the financial return of one pig place.
The goal of the current study was to examine how the number of feeding phases and variation in pigs affect returns to capacity unit (housing capacity for one fattening pig), feeding and slaughter timing. The problem was studied with a dynamic programming model, which solves the optimal feeding and slaughter policies simultaneously as described in Niemi (2006) and with Monte Carlo simulation. The models characterize growth process explicitly, taking into account weight, carcass composition and genotype of pigs, as well as interactions between feeding, genotype and quality-adjusted carcass value. The state of the pig was measured by fat content and lean mass contained in the pig, its live weight and the distribution of weight and the genotype. Variation in growth potential was simulated with the mean growth at a given state and confidence intervals of the mean growth potential. The analysis compares: (1) multiphase feeding optimized daily; (2) multi-phase feeding optimized weekly; (3) two-phase feeding; and (4) $50 \%$ decrease in variation in genotype-specific parameters.

Feeding regime shifts towards a protein-rich diet, when switching from the two-phase to multi-phase feeding, which takes into account changes in growth potential thoroughly. When adjusting the feed according to the pig's weight, emphasis is on the weeks prior to slaughter when genotypes make distinctions. A switch from two-phase to multi-phase feeding increases returns to capacity unit by $€ 2 \cdot 4$ per year, from weekly to daily adjustment by $€ 6.9$ per year and a $50 \%$ decrease in variation in pigs by $€ 13.3$ per year. In general, producers benefit from segregated management policy, but the variation in pigs can reduce returns. An increase in variation in pigs can reduce particularly the market value of pigs.

Keywords: Optimization Modelling, Dynamic Programming, Simulation, Pig

NiEMI, J. K. (2006). Dynamic programming model for optimizing feeding and slaughter decisions regarding fattening pigs. PhD Thesis, The University of Helsinki, Helsinki, Finland. Available on-line at: http://urn.fi/URN:ISBN: 951-729-997-4 (verified 22 Nov 2007).

Embedding Dynamic Statistic Prediction models into a Markov Decision Process. L. R. NIELSEN ${ }^{1}$ AND E. JØRGENSEN'2. ${ }^{1}$ Research Unit of Statistics and Decision Analysis, University of Aarhus, ${ }^{2}$ Genetics and Biotechnology, Faculty of Agricultural Sciences, University of Aarhus, PO Box 50, 8830 Tjele, Denmark

Some preliminary results of a newly started project on developing decision support on dairy farms have been given. One goal is to build a Markov Decision Process (MDP) on cow level based on in-line measurements in 
milk. These are readily available and the sensors register several variables. It is important that relevant traits/states of the cow can be forecasted in the MDP. This can be done using Dynamic Statistic Prediction (DSP) models which must be embedded into the MDP. General ideas on how to embed DSP models into the overall MDP have been presented. Moreover, the behaviour of the model are being shown on in-line measurement data from the project.

Keywords: OR in Agriculture, Dynamic Programming

\section{Ideas around steady state in herd models. S. V. RODRÍGUEZ-SÁNCHEZ AND L. M. PLÀ- ARAGONĖS. Department of Mathematics, University of Lleida, Jaume II, 7325001 Lleida, Spain}

In general, livestock research models are based on steady state (Plà 2007). Upton (1989) enumerated cases in which the use of steady state is advisable for instance in the livestock productivity assessment, evaluating systems, or in comparing alternative planned options. Different authors like Jalving et al. (1992) compared different management strategies by using steady-state models. However, this approach can produce problems during use in field conditions. Hence, the aim of the current study is the discussion about the benefits of the steady-state modelling and the practical consequences of an indiscriminate use.

Steady state in herd management attempts to keep the herd size and structure at equilibrium over time. This fact is relevant allowing the model to be a good predictor of farm performance when stability is achieved. Development of a model requires some assumptions to be employed. If these are correct, the model will be a good predictor of the farm productivity. Calculations can be performed by simulation or be derived analytically as was illustrated by Baptist (1992). Analytical methods include differential equations, actuarial tables and transition matrices. Simulation requires the setting of a number of runs and steps per running in combination with some criterion of stability.

Farms are subject to variability and this may affect how to reach or maintain the steady-state situation in real instances. Therefore, transient stages cannot be neglected due to their importance in field conditions. It is concluded that models based on steady state are essential to compare different management strategies for a long time horizon. However, it is also important to develop new models to support decision in transient situations.

Keywords: Herd Management, Steady State, Transient stage, Herd Modelling.
BAPTIST, R. (1992). Derivation of steady state herd productivity. Agricultural Systems 39, 253-272.

Jalving, A. W., DiJkhuizen, A.A. \& VAN ARendonk, J.A. M. (1992). Dynamic probabilistic modelling of reproduction and management in sow herds: general aspects and model description. Agricultural Systems 39, 133-152.

PLÀ, L. M. (2007). Review of mathematical models for sow herd management. Livestock Science 106, 107-119.

Upton, M. (1989). Livestock productivity assessment and modelling. Agricultural Systems 43, 459-472.

On using stochastic integer programming for forestry management. L. F. ESCUDERO ${ }^{1}$, A. ALONSOAYUSO $^{2}$, M. GUIGNARD-SPIELBERG ${ }^{3}, M$. QUINTEROS ${ }^{4}$ AND A. WEINTRAUB ${ }^{4} .{ }^{1}$ Centro de Investigacion Operativa, Universidad Miguel Hernandez, 03202 Elche, Spain. ${ }^{2}$ Statistics \& Operations Research Department, Rey Juan Carlos University, c/Tulipan s/n, 28933 Móstoles, Spain. ${ }^{3}$ Operations and Information Management (OPIM), Wharton University of Pennsylvania, 191046340 Philadelphia, USA. ${ }^{4}$ Departamento de Ingeniería Matemática (DIM), University of Chile, Santiago de Chile, Chile

The problem addressed in the current work consists fundamentally of a land-management system designated for wood production. For each time period, the planner must decide which units to cut and what access roads to build in order to maximize expected net profit. A multistage Stochastic Integer Programming model is presented. It enables the planner to make more robust decisions based on a range of price scenarios over time, maximizing the expected value instead of merely analysing a single average scenario. A specialization of the Branch-and-Fix Coordination algorithmic approach is presented.

Keywords: Forestry Management, Stochastic Programming

\section{A linear programming-based application for supporting strategic decisions in forestry. M. RUIZ-TAGLE ${ }^{1}$ AND G. PAREDES ${ }^{2}$. Instituto de Informática, Universidad Austral de Chile, Campus Miraflores, Valdivia, Chile. ${ }^{2}$ Instituto de Manejo Forestal, Universidad Austral de Chile, Campus Isla Teja, Valdivia, Chile}

Strategic planning of resource allocation in forest companies involves several decisions that have a relevant impact over a long term due to the temporal dimensionality of forest management. A typical optimization problem in a large forest company may 
require 200000 decision variables and 80000 constraints due to the number of stands, management regimes, harvest options, type of products and length of the planning horizon. These problems were formerly solved with simplified simulation techniques that did not guarantee optimality.

To the basic forest optimization problem presented by Johnson \& Scheurman (1977) as 'Model II' in a linear programming (LP) form, the present authors have incorporated a set of constraints and variables to allow the configuration of more specific planning scenarios, which can be customized by the Decision Maker (DM) by means of a software application.

The design of a software platform was considered that enables the user to apply a four-phase methodology to solve the planning problem. The first phase consists of loading the database and the configuration of spatial and temporal resolution. Data validation, consistency verification and computation of economic coefficients are the main tasks in the second phase. These coefficients, Net Present Value and Soil Expectation Value, are calculated for all forests considering species, management regime, localization, site and initial age, for all possible harvest ages and for all possible situations as ending inventory. The visualization of these coefficients allows the DM a second-level validation through a comparison among different kinds of forests.

In the third phase, the LP matrix is generated and constraints chosen by the DM are activated, forming therefore the planning scenario. The geometry of non-zero data within the LP matrix is considered for a fast and efficient matrix generation. The matrix generator together with the module for configuration of the planning scenario, form a powerful and robust tool for the DM in this kind of problem, allowing him to focus his efforts on the selection of constraints that best represent the economic scenario being modelled.

Finally, in the fourth phase, a solver module from an optimization library is called, the optimal solution is loaded and decoded, and planning reports are generated.

This application is being used routinely by the main forest companies in Chile. The superior management levels rely now on a tool that guarantees optimality as well as parametric and sensitivity analysis of largescale resource allocation problems.

Keywords: Forestry Management, Linear Programming

Johnson, K. N. \& Scheurman, H. L. (1977). Techniques for Prescribing Optimal Timber Harvest and Investment under Different Objectives-Discussion and Synthesis. Forest Science Monograph 18. Washington, DC: Society of American Foresters.
Applying case-based reasoning in a laser scanner forest inventory system. C. NUGENT, T. NORDLANDER, S. PRESTWICH AND J. LITTLE. Cork Constraint Computation Centre, University College Cork, Ireland

TreeMetrics Ltd. has developed a laser scanning inventory technology that provides accurate stem profile and curvature information for each tree in a survey plot. A challenge facing TreeMetrics is the stem profile prediction when occlusion occurs. Traditional approaches to stem prediction are rigid and do not fully utilize the rich data available from the laser scanner. Case-based reasoning is an artificial intelligence method for solving problems by using or adapting solutions to similar past problems; we apply this method to solving the stem profile prediction task in a flexible and adaptable way.

Keywords: Forestry Management, Data Mining, Artificial Intelligence

Modelling forest core area with integer programming. M. CONSTANTINO. University of Lisbon, Cidade Universitária, 1749-016 Lisbon, Portugal

Consider a forest to be managed for timber production, but where conditions for wildlife habitat are favoured. One typical requirement for some animals is the existence of regions of mature forests that are far away from the areas that are clear-cut, called core regions. An integer programming model is presented to maximize the value of the timber harvested, subject to minimum core area constraints. The model also includes harvest flow and ending inventory requirements. Computational results and their analysis for a simulated landscape are also presented.

Keywords: Forestry Management, Integer

Programming, Environmental Management

A two-stage stochastic optimization model for allocating a total allowable catch quota in the Chilean Jack mackerel (Trachurus murphyi) fishery. V. M. ALBORNOZ ${ }^{1}$ AND C. M. CANALES ${ }^{2} .{ }^{1}$ Departamento de Industrias, Universidad Técnica Federico, Santa María 6400, Santiago, Chile, ${ }^{2}$ Instituto de Fomento Pesquero (IFOP), Blanco839, Valparaíso, Chile

In the current paper, the methodology proposed for the computation of an optimal total allowable capture quota as a planning tool in the exploitation of the Chilean Jack mackerel (Trachurus murphyi Nichols) is presented. 
In Chile, the most important fishing regulation instrument is the establishment of global and individual capture quotas for each species, whose levels are based on a total allowable capture and set annually by the Ministry of Fisheries, in agreement with the legal framework. The current work and previous applications (cf. Albornoz \& Canales 2006) were precisely done in close cooperation with the Fisheries Development Institute (IFOP), one of whose tasks is to give the technical support to the decision making of state agencies with respect to each year's total allowable capture quota that contributes to the fishery management.

More precisely, the proposed model seeks to preserve the renewable marine resource during a long-term planning horizon with decisions that are also efficient from a bio-economic perspective. In particular, the model corresponds to a two-stage stochastic nonlinear programming model with recourse (Birge \& Louveaux 1997). In the model, the total allowable capture quota for the first year is defined as a first-stage decision variable that can be implemented independently of any particular scenario of the uncertain parameters. The remaining decisions variables, related to capture quotas in the next years of the planning horizon and the size of the population considering the age structure and its exploitation zones, are dependent on the different specific scenarios, defining the second-stage decision variables necessary to provide the flexibility needed to deal with uncertainty. The decisions are based on the knowledge of the population dynamic behaviour, represented through numerous mathematical equations with age structures of the population and its migratory process between the exploitation zones of the resource (Clark 2005; Haddon 2001).

The results show that the use of a stochastic optimization model, combined with the use of a population dynamic model with an age structure and self-generating by means of recruiting, provides a useful methodology for the analysis, control and sustainable and efficient management of this particular fishery resource.

Keywords: Fishery Management, Optimization Modelling, Stochastic Programming

Albornoz, V. \& Canales, C. (2006). Total allowable catch for managing squat lobster fishery using stochastic nonlinear programming. Computers \& Operations Research 33, 2113-2124.

Birge, J. \& Loveaux, F. (1997). Introduction to Stochastic Programming. New York, USA: Springer Verlag.

Clark, C. W. (2005). Mathematica Bioeconomics: Optimal Management of Renewable Resources, 2nd Edn. New York, USA: Wiley.

Haddon, M. (2001). Modelling and Quantitative Methods in Fisheries. Boca Raton, Florida, USA: Chapman \& Hall.
Optimizing fishing and fish processing in Iceland. E. I. ASGEIRSSON ${ }^{1}$ AND S. MARGEIRSSON ${ }^{2}$. ${ }^{1}$ School of Science and Engineering, Reykjavik University, Kringlan 1, 103 Reykjavik, Iceland, ${ }^{2}$ Icelandic Fisheries Laboratories, University of Iceland, Skulagata 4, 101 Reykjavik, Iceland

An ambitious project for optimizing and analysing the fishing industry in Iceland is presented. The project is twofold. The first part of the project focuses on gathering historical data and combining the data into a centralized research database. Each fishing company that participates in the project has a local database which is used to gather data for statistical analysis and to estimate input parameters for the optimization model. All participants in the project can share their data with other participants or keep their own data separate. Each participant shares data with a research database at the Icelandic Fisheries Laboratories and this centralized database will be used for research purposes.

The second part of the project is a linear optimization model that maximizes the revenue of a fishing company. The model uses the historical data gathered from leading Icelandic fishing companies to determine the optimal fishing grounds, ideal expected catch and the best processing methods for a catch over a time period, while maximizing the overall revenue of the fishing company. The optimization model includes both detailed routing of the fishing fleet and the allocation of the catch, whether to sell the catch directly on the market or to process the catch. The model also selects which products the processing should focus on, based on the expected available material. The present authors use historical data for each fishing ground and for each time of the year to estimate the quantity of each fish species that the ships are expected to catch in a specific fishing ground at a specific time of the year.

As far as is known, connecting the location and time of year of the fishing fleet and the expected catch with the revenue of a fishing company has not been done before. This is also the first time that leading Icelandic fishing companies gather their forces to create a detailed centralized database of the fishing grounds and the fish processing, which will be used for research purposes while each participant can also use the historical data for statistical analysis and to optimized planning.

\section{Keywords: Industrial Optimization, Optimization Modelling, Linear Programming}


Perturbation analysis for the stationary distribution of a Markov chain representing the productive lifespan of herd sows. G. PÉREZ-LECHUGA ${ }^{1}$ AND L. M. PLÁ ${ }^{2} .{ }^{1}$ Advanced Research Center of Industrial Engineering, Hidalgo State University, Pachuca, Hidalgo, Mexico, ${ }^{2}$ Department of Mathematics, University of Lleida, Jaume II, 73, E-25001 Lleida, Spain

In the current paper, the animal replacement problem using a Markov decision process is considered. The model represents the productive and reproductive lifespan of herd sows assuming that the population is in steady state under an infinite planning horizon. A linear programming (LP) model is employed to find the optimal policy that contributes the maximum average reward per stage (Tijms 1994). The objective, once the optimal policy is obtained, is to perturb some elements of the transition probabilities matrix and to evaluate their effects on the solution. Firstly, an approximation method is employed, differentiating the optimal basis of the LP model used to optimize the Markov chain. The optimality and the corresponding feasible conditions for the perturbed problem are derived. Later on, the matrix perturbation is analysed from a probabilistic viewpoint and the perturbed quantities are approximated by a first-order perturbation expansions. This permits the computation of statistics estimating the variation in the perturbed quantity and in the optimal solution of the original problem. The Frobenius norm and the stochastic norm are used to bound errors. The global purpose of this paper is to determine the existent correspondence among the classical matrix perturbation theory and the obtaining of optimal policies in the application of Markov decision programming to animal production models. To illustrate our proposal, a simple version of the sow replacement problem developed in Plà et al. (2003) is considered; the system exists in a sow farm where sows are allowed to reach nine reproductive cycles as maximum and at the end of the cycle, two actions can be taken: keep or replace. The problem is represented as a regular Markov decision process and solved using an LP model. Transition probabilities and reward values are arbitrary but near to what are observed in actual systems; the corresponding transition probabilities matrix is perturbed using the mentioned techniques and the optimal policies are characterized in terms of these. The theoretical and practical results are reported. These are promising for coping with the dimensionality problem in dynamic programming problems and sensitivity analysis.

Keywords: Herd management, Stochastic Programming, Perturbation Analysis, Sows
Plì, L. M., Pomar, C. \& Pomar, J. (2003). A Markov decision sow model representing the productive lifespan of herd sows. Agricultural Systems 76, 253-272.

Tisms, H.C. (1994). Stochastic Models-an Algorithmic Approach. New York, USA: Wiley.

Production planning in farms. B. VIZVARI. Operations Research, Eotvos Lorand University, 1117 Budapest, Hungary

A stochastic programming model is discussed to determine the use of the arable land in farms. The goal is to achieve certain production quantities on an a priori given probability level. The stochastic programming problem is of a new type.

Keywords: OR in Agriculture, Stochastic Models

Trade-offs between economic and environmental criteria in irrigated agriculture: the case of the Monegros County in Spain. S. ELFKIH ${ }^{1}$, C. ROMERO ${ }^{2}$ AND M. L. FEIJOO ${ }^{1}{ }^{1}$ Departamento de Análisis Económico, Universidad de Zaragoza, 50005 Zaragoza, Spain. ${ }^{2}$ Forest economics and management, ETS Ingenieros Montes, Technical University of Madrid, Ciudad Universitaria $s / n$, 28040 Madrid, Spain

In the current paper, the degree of conflict and the trade-offs between environmental and economic criteria within a context of irrigated agriculture are analysed. The proposed method is based upon multiobjective programming and goal programming. The method is applied to the 'Monegros' County, which is a representative area of irrigated agriculture in Spain. Monegros County currently suffers serious environmental problems, such as saline contamination of aquifers and drainage water. Some empirical findings as well as some methodological insights are presented.

Keywords: OR in Agriculture, Environmental Management, Multi-Objective Decision Making

A comparative analysis of the sustainability of rice cultivation technologies using the Analytical Network Process. E. REIG ${ }^{1}$, J. AZNAR ${ }^{2}$ AND V. ESTRUCH ${ }^{2} .{ }^{1}$ Departament d'Economia Aplicada II (Facultat d'Economia, Universitat de València). ${ }^{2}$ Departament d'Economia $i$ Ciències Socials, Escola Tècnica Superior d'Enginyeria Agronòmica, Universitat Politècnica de València, Spain

Rice cultivation in Mediterranean wetlands represents a system of land management that performs 
important non-marketable functions, like protecting biodiversity and shaping traditionally valued landscapes (Fasola \& Ruiz 1997). The Albufera Natural Park, in the vicinity of Valencia (Eastern Spain), is a protected wetland area of this sort. Local rice farmers are currently benefiting from agricultural support measures and agro-environmental payments, under the European Common Agricultural Policy. But lack of financial viability could precipitate abandonment, with undesirable consequences from an environmental viewpoint.

In the current paper an analysis of the sustainability - economic, environmental and sociocultural-of three alternative rice cultivation techniques that could be put to use in the Albufera rice fields is undertaken. The first choice is the current system, which includes some restrictions on input use and cultivation practices, in order to fulfil the park's environmental regulations. The second is an alternative conventional production system, with no environmental restrictions attached, but allowing for the physical restructuring of rice plots. The final choice is a full-fledged ecological cultivation system being considered for implementation.

All the three techniques have been evaluated and the following criteria have been considered: shortand long-term economic competitiveness, impact on air and water quality, impact on landscape and biodiversity, cultural heritage related to different hydrological systems, and ability to foster job creation and economic activity. Multi-criteria decision methods have been used before to evaluate agricultural practices (Parra et al. 2005; Karami 2006). The current paper shows that the Analytical Network Process (ANP) method is perfectly suited to deal with the complex interrelations involved in sustainability evaluation. Using this method it is demonstrated that the ecological cultivation system is the most sustainable technique. The current system ranks second, while the conventional unrestricted system gets the third place. The computations also show that if only the economic dimension of sustainability were to be considered, the order would be reversed, with the conventional and ecological technologies changing places and the current system remaining in the second place.

Keywords: OR in Agriculture, Analytic Network Process, Multi-Objective Decision Making

Fasola, M. \& Ruíz, X. (1997). Rice farming and waterbirds: integrated management in an artificial landscape. In Farming and Birds in Europe: The Common Agricultural Policy and Its Implications for Bird Conservation. (Eds D. J. Pain \& M. W. Pienkowski), pp. 210-225. London: Academic Press.

Karami, E. (2006). Appropriateness of farmers' adoption of irrigation methods: the application of the AHP model. Agricultural Systems 87, 101-119.
Parra, C., Calatrava, J. \& De haro, T. (2005). Evaluación comparativa multifuncional de sistemas agrarios mediante AHP: Aplicación al olivar ecológico, integrado y convencional de Andalucía. Economía Agraria y Recursos Naturales, 5 27-55.

Environmental costs in routing design: an algorithm implementation. J. FAULIN, J. M. PINTOR, F. LERA, S. UBEDA AND J. SAN MIGUEL. Department of Statistics and Operations Research, Public University of Navarre, 31006 Pamplona, Navarre, Spain

Increasing environmental concerns arising from economic activities have shifted to the transportation and logistics arena in recent decades. In fact, research into transport externalities has led to the concept of sustainable mobility. Road transport is the source of 0.9 of the transportation external costs, 0.3 of which are due to road freight transport.

The current study analyses route-building procedures using a pertinent variant (in this instance called algorithm with environmental criteria (AEC)), that is, of the traditional algorithms (Clarke \& Wright 1964; Mole \& Jameson 1976) for the Capacitated Vehicle Routing Problem. Apart from the classic costs based on distances, this method includes others such as environmental costs.

The estimation of environmental costs is not easy, because it requires complex computations to approximate the negative environmental impact of transport activities. Moreover, environmental cost estimation must be linked to specific geographical areas, and requires data on the exact delivery policies for each vehicle (European Conference of Ministers of Transport 2003; Carlow 2001). Taking these considerations into account, complete solutions to ten real cases P1-P10 were found (see ETMOL study in Pintor et al. 2005). Thus, it was obtained that the consideration of environmental costs usually involves a $29 \%$ cost increase, roughly speaking, in relation to the initial scenario.

The performance of the AEC with different baseline methods for ten instances drawn from Augerat (1995) with the best-known solutions are also compared. Taking into account the simplicity of the baseline methods used, the solutions generated by AEC methods are not highly accurate. The AEC method therefore generated solutions for the problems shown involving total distances that are $17.5 \%$ greater than the best-known solutions using Clarke \& Wright as the baseline method and $9.95 \%$ greater taking Mole \& Jameson as the baseline method. These cost increases highlight the importance of environmental costs in transport policies.

Keywords: Routing, Environment Management, $\mathrm{OR}$ in Agriculture. 
Augerat, P., Belenguer, J. M., Benavent, E., Corberán, A., Naddef, D. \& Rinaldi, G. (1995). Computational Results with a Branch and Cut Code for the Capacitated Vehicle Routing Problem. Research Report 949-M, Universite Joseph Fourier, Grenoble, France. Available online at http://branchandcut.org/VRP/data/ (verified 26 Nov 2007).

CARlow, P. (2001). Handbook of Environmental Risk Assessment and Management. Oxford: Blackwell Science.

Clarke, G. \& Wright, J. W. (1964). Scheduling of vehicles from a central depot to a number of delivery points. Operations Research 12, 568-581.

European Conference of Ministers of Transport (ECMT) (2003). Safe and sustainable transport: a matter of quality assurance. In Proceedings of the International Seminar, Prague, March 2001. Paris, France: Organization for Economic Cooperation and Development (OECD).

Mole, R. H. \& Jameson, S. R. (1976). A sequential routebuilding algorithm employing a generalised savings criterion. Operational Research Quarterly 27, 503-511.

Pintor, J. M., Faulin, J., Lera, F., Garcia, J., San miguel, J. \& Ubeda, S. (2005). Economic and Safety Effects in the Goods Transport Vehicles for Logistic Carriers, 2004-2005. ETMOL Project Report, Spanish Ministry of Transport, Madrid (in Spanish). Available online at http://www.imac.unavarra.es/ETMOL/ (verified 26 Nov 2007).

A portfolio theory approach to crop planning under environmental constraints. C. Z. RADULESCU ${ }^{1}$, M. RADULESCU ${ }^{2}$ AND S. RADULESCU ${ }^{2}$. ${ }^{1}$ National Institute for Research and Development in Informatics, 8-10 Averescu Avenue, 011455, Bucharest 1, Romania, ${ }^{2}$ Institute of Mathematical Statistics and Applied Mathematics, Casa Academiei Romane, Calea 13 Septembrie nr.13, RO050711, Bucharest 5, Romania

The aim of the current paper is to present a multicriteria model for crop planning in agriculture. The approach is based on the portfolio theory. The model takes into account weather risks, market risks and environmental risks. Input data includes historical land productivity data for various crops and soil types, historical market prices data for crops, yield response to fertilizer and pesticide application, unitary costs of fertilizers and pesticides, costs for cultivation of the crops (without using fertilizers and pesticides) on the plots.

The model considers a farm which has its land divided into several plots $P_{1}, P_{2}, \ldots, P_{m}$. One assumes that if a plot is cultivated, then it is cultivated with the same crop. Also one assumes that the soil quality of a plot is homogeneous. The farmer has to choose a crop plan from $\mathrm{n}$ crops $C_{1}, C_{2}, \ldots, C_{n}$. In order to obtain high yields the farmer uses fertilizers and pesticides.

For each fertilizer and pesticide one considers two environmental levels: the desirable level and the maximum admissible level. Monetary penalizations for exceeding the environmental levels are considered. The environmental risk is defined as the sum of the penalties for exceeding the environmental levels.

The financial risk is defined as the variance of the return of a crop plan.

The decision variables are the matrices $\mathbf{x}=\left(x_{i j}\right)$ and $\mathbf{y}_{i j}=\left(y_{i j 1}, y_{i j 2}, \ldots, y_{i j k}\right) i \in\{1,2, \ldots, n\}, j \in\{1,2, \ldots, m\}$. Here, $x_{i j}$ is the decision variable that takes the value 1 if the crop $C_{i}$ is cultivated on plot $P_{j}$ and takes value zero if the crop $C_{i}$ is not cultivated on the plot $P_{j} \cdot y_{i j r}$ is the decision variable representing the quantity of fertilizer or pesticide $r$ used for the cultivation of one unit area of plot $P_{j}$ with crop $C_{i}$.

A multi-criteria model and four single-criteria mixed integer programming problems are formulated that are derived from the multi-criteria model:

- the minimum environmental risk problem;

- the minimum financial risk problem;

- the maximum expected return problem; and

- the risk - expected return trade-off problem.

In the minimum environmental risk problem, the manager tries to minimize the environmental risk taking into account the following restrictions:

- the expected return is greater than a given level $W$;

- the expected quantity of crop $C_{i}$ is greater than a given number $Q_{i}$;

- the sum invested in the production plan lies in the interval $\left[M_{1}, M_{2}\right]$; and

- the financial risk is smaller than a given level $\tau$.

Under some assumptions, it is proved that the above problem is equivalent to a mixed integer programming problem with a linear objective function and linear and quadratic constraints.

A numerical example for this problem is discussed.

Keywords: OR in Agriculture, Environmental

Management, Mathematical Programming

\section{A multi-criteria approach for agricultural policy mak- ing. F. J. ANDRÉ AND L. RIESGO. Department of Economics, Universidad Pablo de Olavide, Ctra. Utrera km.1, 41013 Seville, Spain}

A typical economic problem is that of finding an optimal policy in the sense of choosing the value of a set of policy instruments to optimize some policy objective or a social welfare function. In this case, we are concerned about the optimal design of policies in the field of agricultural activity.

Agriculture is typically a multi-dimensional activity. Some authors have pointed at the fact that agriculture performs several important social, economic and environmental functions, such as providing food and other produce, contributing to the survival of rural communities, biological diversity and so on. 
Moreover, different policy objectives could conflict to some extent. For example, maximizing agricultural productivity could be harmful to the environment, and increasing agricultural employment might conflict with profitability.

It can be concluded that the optimal design of agricultural policy can be seen as a genuine multicriteria problem, although it is not common in the literature to model policy making as a Multi-Criteria Decision Making (MCDM) problem. A methodological proposal is presented to approach agricultural policy making as an MCDM problem.

The main idea is to model the decision making problem of the agricultural authority as determining the value of the policy instruments to optimize the policy objectives subject to any constraints on the policy instruments and a set of equations representing the behaviour of farmers (i.e. the response of farmers to the policy scenario). It is proposed to do this by incorporating the first-order conditions of the farmers' decision problem as constraints for the policy maker.

In order to represent the behaviour of farmers in an operational way, some elicitation of their MultiAttribute Utility Function (MAUF) is needed. A multiplicative specification is chosen that has the advantage that the first-order conditions involve the farmers' decision variables, so that they provide relevant information for the policy maker. To elicit the parameters of the MAUF, a non-interactive method proposed by André \& Riesgo (2007) is followed.

To illustrate the potential usefulness of this approach, an application to a Spanish agricultural sector located in the Douro basin is presented. A bi-criteria policy problem is considered involving a private objective (enable farmers to achieve the maximum value for their utility) and a public objective (minimize the environmental impact of nitrogen). Water tariffs, subsidies and nitrogen taxes are considered as agricultural policy instruments. The approach enables a measurement of the degree of conflict between both objectives with real data. In a second step, the set of efficient agricultural policies defined as those policies which are not Pareto-dominated are presented. Finally, the set of compromise agricultural policies as those policies which are closer to the ideal point according to standard L-p metrics is identified.

Keywords: Multi-Criteria Decision Making, Multi-Attribute Utility Function, Agricultural Policies, Spanish Agricultural Sector.

André, F. J \& Riesgo, L. (2007). A non-interactive elicitation method for non-linear multi-attribute utility functions: theory and application to agricultural economics. European Journal of Operational Research 181, 793-807.
Environmental decision support for the forestry sector in the framework of the Rio Conventions. R. D. CÓNDOR ${ }^{1}$, A. SCARELLI ${ }^{2}$ and R. VALENTINI'. ${ }^{1}$ DISAFRI, Universitá degli studi della Tuscia, Via S. Camino Lellis, Viterbo $01100-$ Italy, ${ }^{2}$ DECOS Universitá degli studi della Tuscia, Via S. G. Decollato 1, Viterbo 01100 - Italy

In the context of multilateral environmental agreements, the so-called Rio Conventions, which include the United Nations Framework Convention on Climate Change (UNFCCC), the Convention on Biological Diversity (CBD) and the United Nations Convention to Combat Desertification (UNCCD), have recognized the importance of establishing synergies. Yet, at local level, cooperation in the development of methodologies and tools for implementing synergies is needed (UNFCCC 2004). The current work describes a real case study of environmental decision support for the forestry sector, in the framework of the Rio Conventions, in which MultiCriteria Decision Aid is used.

A comprehensive study of the forestry ecosystem services from the global and local point of view has been done. Different aspects, such as the implementation of a global scope at a local level, the Rio Conventions' objectives and principles, and the stakeholders involved in the process are considered. Later, from the methodological point of view, multicriteria evaluation appears to be an adequate assessment framework for sustainability policies and a very efficient tool to implement a multi-inter-disciplinary approach (Munda 2005).

It has been identified that policymakers were interested in evaluating international forestry projects within the framework of the Rio Conventions. Therefore, a set of forestry criteria have been developed based on the identification and selection of appropriate attributes. Consequently, a questionnaire was sent to forestry experts participating in the Rio Convention process to validate these criteria. Moreover, criteria interaction have been appreciated, so is the correlation between the importance of criteria and the provenance of participants. Later, it has been demonstrated that the multi-criteria method adopted can be a useful tool for policymakers when sorting forestry projects into predefined ordered categories. At the end, the decision-aiding process has been helpful in organising a complex and real environmental situation, converge expectations toward a direction, and in supporting the implementation of synergies among the Rio Conventions at a local level.

\section{Keywords: Forestry Management, Multi-Criteria Decision Aids, Sustainable Development}

United Nations Framework Convention On Climate Change (2004). Options for Enhanced Cooperation Among 
the Three Rio Conventions, Note by the Secretariat. (Document No. FCCC/SBSTA/2004/INF.19). Geneva, Switzerland: United Nations Office at Geneva. Available online at http://unfecc.int/resource/docs/2004/sbsta/ inf19.pdf (verified 26 Nov 2007).

Munda, G. (2005). Multiple criteria decision analysis and sustainable development. In Multiple Criteria Decision Analysis: State of the Art Surveys (Eds J. Figueira, S. Greco, \& M. Ehrgott), pp. 954-958. New York, USA: Springer-Verlag Inc.

\section{Portfolio analysis with imperfect information: a comparison of quadratic and utility efficient programming. M. VAN ASSELDONK ${ }^{1}$, J. B. HARDAKER ${ }^{2}$ AND G. LIEN ${ }^{3} .{ }^{1}$ Institute for Risk Management in Agriculture, Wageningen University and Research Centre, 6706 KN Wageningen, The Netherlands, ${ }^{2}$ School of Economics, University of New England, NSW 2350 Armidale, Australia, ${ }^{3}$ Norwegian Agricultural Economics Research Institute, 0030 Oslo, Norway}

Historical data on yields and prices useful for farm planning under uncertainty are typically sparse due to lack of relevant records. The use of such data means that sampling bias could lead to unreliable plans. This problem is explored using Monte Carlo methods to illustrate the possible bias for a typical Norwegian mixed farm.

Initially, the Multi-Variate Kernel Density Estimate (MVKDE) method is applied to smooth historical activity gross margins (GM) (Richardson et al. 2006). It was assumed that the resultant smoothed distribution represents the true joint distribution of GMs and then sampled from this distribution in Monte Carlo experiments using two risk programming formulations, mean (i.e. expected)variance $(\mathrm{E}-\mathrm{V})$ programming and Utility Efficient (UE) programming. In E-V programming the stochastic dependencies between enterprise returns are represented by covariances, whereas in UE programming the data are allowed to 'speak' via states of nature matrix.

To keep the experiment feasible, the programming models were solved with sample sizes of 5,15 , $20,30,50,100$ and 200 , each with eight replicates, and a sample size of 10 with 100 replicates. For each obtained programming solution, the ex ante certainty equivalent (CE) of net income (NI) was evaluated.

Using E-V programming, the simulated results for CE of NI were obtained. Results show that there can be appreciable differences between solutions even with unrealistically large sample sizes, entailing considerable reduction in CEs. Comparing the E-V results with the UE results, there are few differences between the two and the differences which do occur are mainly trivial.
Keywords: Risk Analysis and Management, Decision Theory and Analysis, OR in Agriculture

Richardson, J. W., Lien, G. \& Hardaker, J. B. (2006). Simulating multivariate distributions with sparse data: a kernel density smoothing procedure, Poster paper contributed to the 26th International Association of Agricultural Economists Conference, Queensland, Australia, 12th-18th August. http://ageconsearch.umn. edu/bitstream/123456789/10149/1/pp060805.pdf (verified 12 Dec 2007).

\section{Application of reference direction approach in DEA by evaluation of agricultural enterprises. J. FRIEBELOVA AND L. FRIEBEL. University of South Bohemia, Faculty of Economics, Studentska 13, 37005 Ceske Budejovice, Czech Republic}

The current paper is focused on assessment of farms from marginal regions, in Less Favourable Area (LFA) by Data Envelopment Analysis (DEA). Farming in marginal regions does not have to be profitable, but it is necessary for social or ecological reasons. Therefore, negative values of outputs are present in the considered set of farms.

A group of 55 farms of similar characteristics is considered. As inputs, total assets, agricultural land area, man effort and fiscal assets are taken into account, and, as outputs, yields in sum and income from operations before tax.

DEA models described by Farrel (1957) and Charnes et al. (1978) assume non-negative values of inputs and outputs. The dataset of the current paper contains negative values and therefore this condition can not be met. For this reason, the generic directional distance model proposed by Chambers et al. $(1996,1998)$ are used to handle these negative data.

Consider a set of units $k=1,2, \ldots, p$, with input levels $x_{i j}, i=1,2, \ldots, m$ and output levels $y_{j k}, j=1$, $2, \ldots, n$ and unit $o \in k$ which is to be assessed. Vector $\mathrm{g}_{x i}\left(\mathrm{~g}_{y j}\right)$ represents possible changes of input (output). The generic directional distance model is as follows:

$$
\max \left\{\begin{array}{l}
\beta_{0} / \sum_{k=1}^{p} \lambda_{k} y_{j k} \geqslant y_{j o}+\beta_{o} g_{y_{j}}, j=1,2, \ldots, n, \\
\sum_{k=1}^{p} \lambda_{k} x_{i k} \leqslant x_{i o}-\beta_{o} g_{x_{i}}, i=1,2, \ldots, m, \sum_{k=1}^{p} \lambda_{k}=1 \\
\lambda_{k}, \beta_{o}, g_{x_{i}}, g_{y_{j}} \geqslant 0
\end{array}\right\} .
$$

This model (1) is valid for the case of variable returns to scale (VRS) and with input and output vectors in $\boldsymbol{R}^{m+n}$. Target values of inputs (outputs) were obtained as product $\mathrm{X}(\mathrm{Y})$ and $\lambda$. 
This method provides efficiency scores similar to radial efficiencies traditionally used in DEA without previous transformation of negative data. The second advantage of this model is the ability to project inefficient units onto the efficiency frontier with a selected direction. This feature is applicable to the application in the current paper, because the model provides each unit with its own path to efficiency representing its improvement potentials.

Efficiency scores are defined by Eqn (2).

$$
\varphi_{o}=1-\frac{\sqrt{\sum_{i}^{m}\left(x_{i o}^{*}-x_{i o}\right)^{2}+\sum_{j}^{n}\left(y_{j o}^{*}-y_{j o}\right)^{2}}}{\sqrt{\sum_{i}^{m} R_{i o}^{2}+\sum_{j}^{n} R_{j o}^{2}}}
$$

Where $\varphi_{o}$ is efficiency for assessed unit $o$,

- $x^{*}{ }_{i o}$ is target value of $i$-th input projected on efficiency frontier,

- $y^{*}{ }_{j o}$ is target value of $j$-th input projected on efficiency frontier,

- $R_{j o}=\max _{k}\left\{y_{j k}\right\}-y_{j o}, j=1,2, \ldots, n$, and

- $R_{i o}=x_{i \mathrm{o}}-\min _{k}\left\{x_{i k}\right\}, i=1,2, \ldots, m$.

Efficient units B, D, F, G and inefficient units A, C, $\mathrm{E}$ are presented. Classical DEA model using radial projection recommends, for point $\mathrm{E}$, raising output 1 to 4387 and output 2 to 6047 . However, it is not always possible to follow this recommendation. For example, for point $\mathrm{E}$ output 2 cannot be changed, therefore directional vector $\mathrm{g}=(1,0)$ was used. With this direction vector, output 2 remains the same and output 1 should rise to $7 \cdot 5$. This projection is depicted with the dotted line. Direction vectors allow restriction of changes of inputs or outputs. For unit A, a projection on efficient frontier is conducted according to direction vector $g=(0,1)$. Projected point for unit A would be in another place on the efficiency frontier, but the model takes into account efficiency frontier from point $B$ to point $G$ (not vertical and horizontal part of that). Therefore, projection of A can go through point $\mathrm{B}$.

Keywords: Efficiency, Data Envelopment Analysis, Performance, Reference Direction Approach, Radial Projection

Farrell, M.J. (1957). The measurement of productive efficiency. Journal of the Royal Statistical Society, Series A, General 120, 253-281.

Chambers, R.G., Chung, Y. \& Färe, R. (1996). Benefit and functions. Journal of Economic Theory 70, 407419.

Chambers, R. G., Chung, Y. \& Färe, R. (1998). Profit, directional distance functions and Nerlovian efficiency. Journal of Optimization Theory and Applications $\mathbf{9 8}$, 351-364.

Charnes, A., Cooper, W.W. \& Rhodes, E. (1978). Measuring efficiency of decision-making units. European Journal of Operational Research 2, 429-444.
Efficiency evaluation of transporting and loading logs in Shafarood forest (Northern Iran). R. $\mathrm{NAGHDI}^{1}$, I. BAGHERI ${ }^{1}, \mathrm{M}$. NIKOOY ${ }^{2}$ AND J. JAVADPOUR ${ }^{1}$. ${ }^{1}$ Department of Forestry, College of Natural Resources, University of Guilan, Sowmeasara, P.O. Box 1144, Iran. ${ }^{2}$ Department of Forestry, College of Natural Resources, University of Tehran, Iran

Harvesting of the forest is one of the important issues for Caspian forest management in northern Iran. The research relating to cost assessment and the efficiency of the logging systems being used dates back to 1930s, but in northern Iran it only started two decades ago. The evaluation of two mechanized logging systems in the Shafarood forests, showed that the skidding cost for whole tree system and the tree length system were 2858 Rials $/ \mathrm{m}^{3}$ and 1504 Rials $/ \mathrm{m}^{3}$, respectively (Feghi 1989). Abeli (1996) compared efficiency and costs of three ground skidding machinery in Tanzania and showed that the observed difference in efficiency of the three machines depended on type and size of the machinery, skill of the operator and the natural slope of the area.

In the current study the production and cost of Timber Jack 450C wheeled skidder and Volvo BM loader were determined for Shafarood forest in northern Iran. The research was carried out in compartment number 25 of 2 nd district, in Nave forest Shafarood, with the altitude ranging between 1030 and $1250 \mathrm{~m}$ asl. In the research, in order to estimate production and cost of a unit volume of wood, work study techniques were used.

Mathematical models of skidding and loading time predictions as functions of effective factors have been presented to help the optimized utilization of a management unit. By employing these models, the mean values of the contributing factors to the models can be determined and thus predict the operation time and cost of skidding and loading. Based on these predictions, labour requirement, number of machineries and funds can be estimated and then appropriate plans be prepared.

Mathematical equation of the skidding time as a function of effective factors

$$
\mathrm{Y}=2.509+0.019 X_{1}+0.428 X_{2}
$$

where $\mathrm{Y}=$ time needed for one round trip (minutes), $X_{1}=$ skidding distance (m) and $X_{2}=$ volume per turn $\left(\mathrm{m}^{3}\right)$.

Mathematical equation of the loading time as a function of effective factors

$$
\mathrm{Y}=7.153+0.047 X
$$

where $\mathrm{Y}=$ time needed for one round trip (minutes), $X=$ volume per $\log \times$ number of $\operatorname{logs}\left(\mathrm{m}^{3}\right)$.

The results show that the mathematical model of skidding time as a dependent variable is a function 
of independent variables of distance and volume. Based on $99 \%$ confidence, the model proved to be valid. The mathematical model of loading time as a dependent variable is a function of independent variables of volume multiplied by numbers of logs. Based on $99 \%$ confidence, the model proved to be valid. The results show that the amount of production and costs for skidding from stump to landing are $20 \cdot 9 \mathrm{~m}^{3} / \mathrm{h}$ and $\$ 5 \cdot 44 / \mathrm{m}^{3}$, respectively. The amount of production and cost for loading are $61.9 \mathrm{~m}^{3} / \mathrm{h}$ and $\$ 0 \cdot 61 / \mathrm{m}^{3}$, respectively. In both skidding and loading operations, delays are important parts of total operation time. Therefore, increasing delay time has a big effect on production cost and with good management, these delays could be decreased.

Keywords: Forestry Management, Optimization Modelling, Transportation and Logistics

Abeli, W. (1996). Comparing productivity and costs of three sub grading machines. Journal of Forest Engineering 81, 33-39.

FEGHI, J. (1989). Evaluation of two harvesting mechanization systems. MSc thesis, University of Tehran, Iran.

\section{Efficiency evaluation of ground skidding system and determining the optimum forest road density network in Caspian forest (Northern Iran). I. BAGHERI AND R. NAGHDI. Department of Forestry, Faculty of Natural Resources, University of Guilan, Sowmeasara, PO Box 1144, Iran}

In the Caspian forests, most timber is extracted by different methods of ground skidding and the logging methods used are cut to length and tree length. Wheeled skidders appeared in northern Iran in the early 1970s and are now widely used. One of the most important requirements for the ground skidding operation is to have an adequate forest road network density. The results of research carried out on the efficiency of ground skidding systems in northern forests of Iran showed that skidding distance has direct and linear relationship with skidding costs (Naghdi et al. 2005). The logging method is one of the important factors in determining type of roads and road network density (Lotfalian 2002). Plamondon \& Favreau (1994) stated that variables such as average production volume per hectare, road construction and repair costs and skidding costs are important factors in estimating optimum skidding distance. They evaluated four logging systems in terms of efficiency and determined the optimal skidding or forwarding distance for them by using the combined road and skidding costs model. Their findings showed that cable skidder system with road construction cost of $\$ 12000 / \mathrm{km}$ had lowest total construction and skidding costs. The current study was carried out in compartment 926 of 9th district in Shafarood forest and the possible harvesting area of compartment was
58 ha. Work study techniques were used to estimate work rate and the unit costs of a volume of wood extract. Variance analysis and multi-variable regression models were used to create mathematical models of task performance time for harvesting machinery. The skidding cost model was used to estimate the skidding cost for one cubic metre of wood extracted over different skidding distances.

Mathematical equation of the skidding time as a function of effective factors

$$
\mathrm{Y}=-3.57+1.88 X_{1}+0.02 X_{2}+0.20 X_{3}+3.09 X_{4}
$$

where $\mathrm{Y}=$ time needed for one round trip (minutes), $X_{1}=$ load volume $\left(\mathrm{m}^{3}\right), X_{2}=$ skidding distance $(\mathrm{m})$, $X_{3}=$ load winching distance (m) and $X_{4}=$ number of logs in each trip.

The road construction costs include excavation and filling, pavement and drainage costs. The planning costs are taken as $0 \cdot 10$ of these costs. The cost of skidding in the ground skidding system and the road construction costs are determined for one cubic metre of wood. Using these costs, the optimum forest road network density is determined for the studied district. The results show that total work rate and skidding costs with delays are $11.43 \mathrm{~m}^{3} / \mathrm{h}$ and $\$ 7.25 / \mathrm{m}^{3}$, respectively. The road construction cost is $\$ 21878 / \mathrm{km}$, the annual road construction cost is $\$ 3535 / \mathrm{km}$. After calculating road construction cost in terms of $\$ / \mathrm{m}^{3}$, the sum of road construction and skidding costs for different road densities are determined. Based on minimizing these two costs, the optimum forest road network density was estimated to be $7-10 \mathrm{~m} / \mathrm{ha}$. The maximum practical skidding distance is $582 \mathrm{~m}$ and the skid trails spacing is $140 \mathrm{~m}$.

\section{Keywords: Forestry Management, Optimization Modelling, Routing}

Lotfalian, M. (2002). Examining effective factors in determining optimum forest roads network. $\mathrm{PhD}$ thesis, College of Natural Resources, University of Tehran, Iran. Naghdi, R., Rafatnia, N., Sobhani, H., Jalali, G. H. \& Hosseini, M. (2005). A survey of the efficiency of Timberjack C450 wheeled skidder in Shafaroud forests in Guilan province. Iranian Journal of Natural Resources 2005; 57(4), 675-688.

Plamondon, J.A. \& Favreau, J. (1994). Establishing the optimal skidding or forwarding distance as a function of road cost. (Technical note TN-000219). Pointe-Claire, Quebec, Canada: Forest Engineering Research Institute of Canada (FERIC).

Solving a multi-period supply chain problem for a pulp industry using Lagrangian heuristics. $H$. GUNNARSSON $^{1}$ AND M. RÖNNQVIST ${ }^{2}$. ${ }^{1}$ Division of Optimization, Linköping Institute of Technology, SE-581 83 Linköping, Sweden, ${ }^{2}$ Department of Finance and Management Science, Norwegian School of Economics and Business Administration, NO-5045 Bergen, Norway 
The problem addressed in the current paper is the supply chain for one of the world's largest suppliers of market pulp, Södra Cell AB. The supply chain considered starts at the supply sources or forest districts and saw mills, located in southern Sweden and then passes through production units or pulp mills and then distribution centres or terminals before ending at the customers' paper mills, located mainly in Europe. Transportation and distribution are carried out by ships, trains, lorries and barges. Decisions about production mix, terminal use and contracts are considered. The planning period is one year and different numbers of time periods are considered. A model for the entire supply chain, including both a large number of continuous variables and a set of binary variables to reflect decisions regarding which terminals to use, is presented. The model becomes large and it is necessary to be able to decompose it in order to get an acceptable solution for the entire planning period. Thus, a Lagrangian heuristic method has been developed based on Lagrangian decomposition (Näsberg 1985; Guignard 1987). The variables concerning storage have been split and then the constraints linking together the old and new variables relaxed. The presented Lagrangian relaxation-based heuristic divides the problem into sub problems for each time period. The heuristic is based on solving the time periods in a rolling horizon, time period by time period. In addition, two variants of a simple heuristic are used in order to compare the solution to the one described. A number of cases based on real data are analysed. The proposed Lagrangian heuristic produces many solutions that can be used to initialize rolling horizon heuristics. These heuristics do, in turn, produce many highquality solutions. In this way, the Lagrangian-based method can be viewed as an intelligent way to produce seeds for heuristics and there are many other tailor-made heuristics that can be developed using the same approach. The rate of convergence is slow in the proposed Lagrangian heuristics method. In order to improve the rate of convergence, a modified subgradient can be used, for example the one suggested by Crowder (1976).

Keywords: Transportation and Logistics, Industrial Optimization, Forestry Management

Crowder, H. (1976). Computational improvements for sub-gradient optimization. Symposia Mathematica 19, 357-372.

Guignard, M. \& Kim, S. (1987). Lagrangian decomposition: a model yielding stronger Lagrangian bounds. Mathematical Programming 39 215-228.

Näsberg, M., Jörnsten, K.O. \& Smeds, P.A. (1985). Variable Splitting-a New Lagrangian Relaxation Approach to Some Mathematical Programming problems. Report No. LiTH-MAT-R-85-04. Sweden: Department of Mathematics, Linköping Institute of Technology.
Software system to support decisions in young bull fattening. J. MAKULSKA ${ }^{1}$ AND A. T. GAWEŁCZYK ${ }^{2}$. ${ }^{1}$ Cattle Breeding Department, Agricultural University, al. 29 Listopada 46, 31-425 Kraków, Poland, ${ }^{2}$ Institut of Environmental Sciences, Jagiellonian University, ul. Gronostajowa 7, 30-387 Kraków, Poland

The software designed to support the optimal decisions in young bull fattening was composed of two modules: optimization of feeding and optimization of fattening strategy. The objective in feeding optimization was to determine the least-cost rations by means of the Linear Programming (LP) simplex algorithm. Optimization of fattening strategy, performed by Dynamic Programming (DP) value iteration, provided the user with the economically optimal sequence of daily gains (or daily gains $\times$ stage lengths) in the subsequent stages of the fattening process and the economically optimal time of replacement with a next bull-calf in cyclic fattening (Kennedy 1986). The following model approaches were considered: (i) fattening to the assumed final weight, (ii) fattening with the assumed length of the planning horizon and (iii) cyclic fattening with the assumed length of the planning horizon and the replacement option.

The software was programmed in Visual Basic and the input variables and parameters were defined in Access data files. They included the feasible daily gains for the mean values in body weight class intervals, daily nutrient requirements for each combination of daily gain and mean body weight in a class interval, nutritional characteristics (IZ-INRA 2001, Board on Agriculture 2000), the availability and prices of feeds as well as the sequence of feeds to be used in the formulation of rations. Final solutions for the module of feeding optimization (characteristics of the optimal feeding rations) and the module of fattening strategy optimization along with other technical and economical results were displayed in separate output windows. The outputs can be processed in an Access database and in an Excel spreadsheet.

Independent from the kind of model approach considered, the relatively high optimal daily gains were determined at the early stages of fattening that indicates that intensive feeding of young bulls is the most efficient. Extending the assumed fattening period caused a decrease in the expected mean optimal daily gains and in economic efficiency. At higher daily costs (direct and non-direct) of fattening, the optimal daily gains usually increased, whereas the optimal slaughter weight decreased, as did the optimal length of the fattening period. The alteration of the production and economic variables considerably influenced the expected economic efficiency of fattening, but the optimal strategy was not very sensitive to the changes in the mentioned variables. It was 
proved that the choice of the kind of model approach should be mostly driven by technological and market considerations.

The developed software system has the potential to be successfully used for gaining insight into efficiency of young bull fattening and, consequently, to support the optimal decisions in various beef production conditions.

Keywords: OR in Agriculture, Optimization Modelling, Mathematical Programming

IZ-INRA. (2001). Standards for Cattle, Sheep and Goat Nutrition (in Polish). Kraków, Poland: Research Institute of Animal Production.

Kennedy, J.O.S. (1986). Dynamic Programming Applications to Agriculture and Natural Resources. London: Elsevier.

Board on Agriculture and Natural Resources (2000). Nutrient Requirements of Beef Cattle, Seventh Revised $E d n$. Washington DC, USA: National Academy Press.

\section{A stochastic branching approach for quantile optimi- zation: application to irrigation planning. $\mathrm{O}$. CRESPO, J.-E. BERGEZ AND F. GARCIA. Biométrie et Intelligence Artificielle, INRA, Chemin de Borde Rouge, 31320, Castanet Tolosan, France}

In response to constant changes in agricultural context, there is a need for adapting agricultural management frequently. Optimization by simulation of agricultural practices can help reach such a goal. Although many papers refer to simulation models of agricultural practices, only few deal with the issue of uncertainty in operation management problems (Bergez et al. 2001). The present paper builds on these few attempts and the problem of simulation-based optimization for generating suitable irrigation strategies is studied.

A new method dedicated to global optimization of continuous input parameters is presented. The approach is validated on an irrigation management problem that has to take into account climate factors and uncertainty attached to them.

The method is based on a stochastic simulation optimization algorithm using branching techniques (Andradóttir 1998; Fu et al. 2005). The procedure consists in a hierarchical decomposition of the parameter space by iteration of three main steps: (i) selection of a promising region, (ii) division of the selected promising region and (iii) simulation and evaluation of the resulting regions. The process is repeated until some stopping criteria are reached, thereby identifying an optimal solution (Bergez et al. 2004).

The simulation step is performed using dynamic models of corn crop and irrigation management process. Irrigation strategies defined as decision rules including variables as temperatures, soil water deficits or irrigation amounts are optimized.

The optimization process is guided by maximization of either an expected value or a quantile of the net margin. The net margin is a weighted sum of yield, water irrigation amount and number of irrigation rounds. The quantile q $\alpha$ of an irrigation strategy $\theta$ is the value such that the probability to achieve the net margin $J(\theta) \geqslant \mathrm{q} \alpha$ is $1-\alpha$. The quantile is used to select interesting sub-regions.

Different options to divide and select the promising region are compared. Comparison is performed with irrigation management process having eight continuous parameters.

Expected value optimization enabled the determination of the most decisive input parameters with respect to the net margin. According to an algorithmic point of view, greedy selection techniques are a good trade-off between speed and efficiency for maximizing the net margin. The way a region is divided has significant impact on the efficiency of the algorithm. For instance dividing a region into two equal parts is interesting if time is limited, but other techniques will be more efficient if time is unlimited.

Quantile optimization showed different results providing alternative management strategies that improve quality of low and high occurrences of direct margins.

This work is a new and efficient approach to design irrigation strategies that can cope with the changing economical and environmental context of agriculture.

Keywords: Simulation-Based Optimization, Bio-decisional Modelling, Irrigation Management

AndradótTiR, S. (1998). A review of simulation optimization techniques. In Proceedings of the 1998 Winter Simulation Conference, Washington DC, 4-7 December (Eds D. J. Medeiros, E. F. Watson, J.S. Carson \& M.S. Manivannan), pp. 151-158. New York: Institute of Electrical and Electronics Engineers, Inc.

Bergez, J. E., Debaeke, P., Deumier, J. M., Lacroix, B., Leenhardt, D., Leroy, P. \& Wallach, D. (2001). MODERATO: an object-oriented decision tool for designing maize irrigation schedules. Ecological Modelling 137, 43-60.

Bergez, J. E., Garcia, F. \& Lapasse, L. (2004). A hierarchical partitioning method for optimizing irrigation strategies. Agricultural Systems 80, 235-253.

Fu, M.C., Glover, F.W. \& April, J. (2005). Simulation optimization: a review, new developments, and applications. In Proceedings of the 2005 Winter Simulation Conference, Orlando Florida, 3-6 December (Eds M. E. Kuhl, N. M. Steiger, F. B. Armstrong \& J. A. Joines), pp. 83-95. New York: Institute of Electrical and Electronics Engineers, Inc. 
The dynamic model of management of roe deer subpopulation. M. HĘDRZAK. Department of Breeding Methods and Management of Farm and Wild Animals, Cattle Breeding Department, Academy of Agriculture in Kraków; Al. 29 Listopada 46, 31-425 Kraków, Poland

Rational game management is a long-term process, and its effects are only visible after many years. In Poland, the management of game has been entrusted to the Polish Hunting Association (PHA). One of the tasks of a hunting district committee is planning the size and structure of shoots in order to keep or change the game numbers in the area of management and/or improve its individual quality.

Population numbers over time are determined by many factors, the influence of which depends on region, intensity and year etc., so the determination of the optimal number of animals designated to be shot, is a very difficult task.

A dynamic model of management of the roe deer (Capreolus capreolus L.) subpopulation, which lives in West Poland, was constructed on the basis of the data collected by workers at the research station of PHA in Czempin over 30 years.

The model enables: (1) the prediction of changes in the number of roe deer depending on different values of initial decision variables, (2) planning of the long-term strategy of harvesting in order to get the determined number and population structures, (3) verification of the plan of shooting in the case of some random factors affecting the population.

It consists of 34 modules connected to each other, which characterize such factors as age and sexual structure in the subpopulation as well as the number of fawns born and the mortality of adult and young individuals, caused mainly by: collisions with mechanical vehicles, poaching, predation by foxes and wandering dogs, mechanical crop gathering and difficult climatic conditions during the winters.

The model was constructed in several stages: (1) the choice of elements characterizing the system, (2) estimation of the parameters which describe it, (3) running many courses of the model with different initial parametric values, (4) comparison of the results from the model with the source data.

The computation in the model was done using Euler's algorithm. The following equation was used to describe the state of the system in every time step:

$$
N(t)=N(t-\mathrm{dt})+(a-b) * \mathrm{dt}
$$

where $N$ is state of subpopulation in the time ' $t$ ', $a$-an input variable, $b$-an output variable, $d t$ - value of the time differential (Matwiejew 1986).

The time unit in the calculations was one year, because the plans and activities to do with game management were set up and executed annually (value of $\mathrm{dt}=1$ ).

One of the practical conclusions from the results obtained in the model is a statement that the current Polish rules of roe deer shooting at about $0 \cdot 20$ of individuals (counted during spring inventory), at the present intensity of the other factors which contribute to decrease in the roe deer population is too high, and most likely would result in a steady decrease in the number of these animals.

\section{Keywords: OR in Agriculture, Mathematical Modelling}

Matwiejew, N.M. (1986). Metody calkowania równań rózniczkowych zwyczajnych. Warsaw, Poland: PWN.

\section{Using a p-median model to optimize harvest in an apple orchard. $M$. GONZÁLEZ-ARAYA ${ }^{1}$ AND M. FERREIRA ${ }^{2}$. ${ }^{1}$ Departamento de Modelación $y$ Gestión Industrial, Facultad de Ingenieria, Universidad de Talca, Merced 437, Curicó, Chile, ${ }^{2}$ Escuela de Ingeniería Civil Industrial, Facultad de Ingeniería, Universidad de Talca, Merced 437, Curicó, Chile}

Most of the literature related to the production process of fruit export presents optimization methods developed and applied to the improvement of activities done within packing, paying little attention to the activities carried out by the fruit growers in the orchards. The present work seeks to improve the efficiency of the harvest activities carried out in an apple orchard located in the region of Maule, Chile, through the application of $p$-median models.

In general, the $p$-median problem can be defined as 'find the location of a fixed number of $p$ facilities so as to minimize the weighted average distance of the system' (Marianov \& Serra 2002).

In the analysed apple orchard, large worker displacements caused by an insufficient number of bins (containers that hold 350 kilograms, approximately) and their inefficient distribution were observed. The location of the bins was done according to the experience of those workers involved in the harvesting process. Therefore, the $p$-median model was applied to evaluate if such locations were optimal; when they were found to be sub-optimal, new location points were proposed.

For $p$-median problem formulation, $p$ bins (potential facilities) were considered to be located in the orchard, aiming to minimize the sum of distances or the sum of time incurred by a harvester when moving from each tree to the closest bin.

Depending on the number of apple trees ready to be harvested, a different number of bins ( $p$ facilities) required locating and, therefore, several $p$-median 
models were formulated and solved. From the obtained solutions, diverse layouts were constructed.

The new layouts allowed a reduction of $10 \%$ in the average harvest time, of $15 \%$ in the average distance travelled by the harvesters and an increase of $11 \%$ in the amount harvested per (day/ harvester/orchard).
Keywords: OR in Agriculture, Location

Marianov, V. \& Serra, D. (2002). Location Problems in the Public Sector. In Facility Location: Applications and Theory (Eds Z. Drezner \& H. W. Hamacher), pp. 119-150. Berlin, Germany: Springer. 